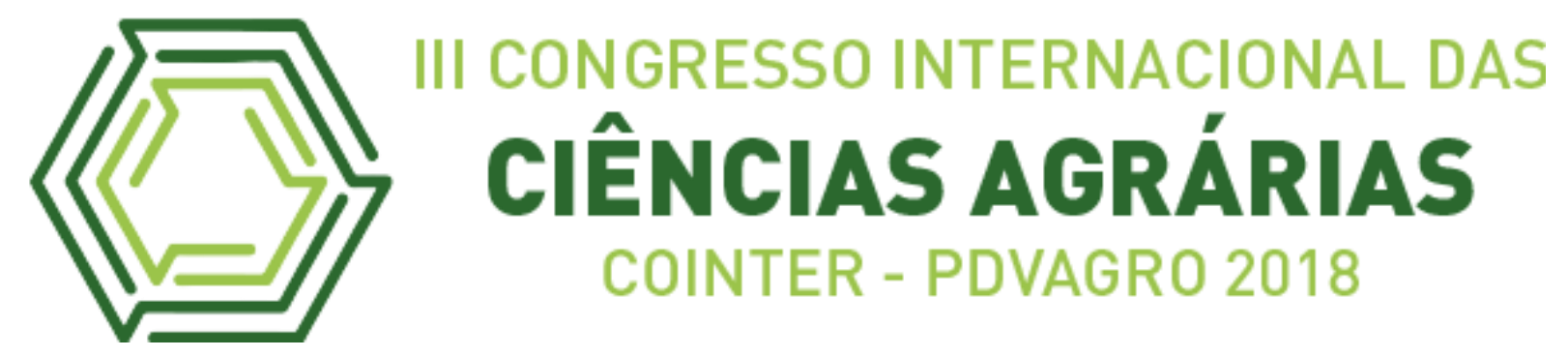

\title{
SEVERIDADE E PROGRESSO DE DOENÇA FOLIAR EM CULTIVARES DE MANDIOCA INDUSTRIAL EM RORAIMA
}

Apresentação: Pôster

Hananda Hellen da Silva Gomes ${ }^{1}$; Everton Diel Souza ${ }^{2}$; Taise Pereira as Silva ${ }^{3}$; Lucas Aristeu Anghinoni dos Santos ${ }^{4}$; Hyanameyka Evangelista de Lima-Primo ${ }^{5}$

\section{DOI: https://doi.org/10.31692/2526-7701.IIICOINTERPDVAGRO.2018.00662}

\section{Introdução}

A mandioca é uma cultura rústica e adaptada às condições de Cerrado, sendo uma das principais fontes alimentares no Brasil, pois é bastante consumida pelas suas raízes, cujo consumo per capita é de $70 \mathrm{~kg}$ ano $^{-1}$, e a maior parte da produção é destina às indústrias de farinha e fécula (Alves et al., 2009). Cerca de $85 \%$ da produção de raízes vem de pequenas áreas de plantio que apresentam baixo rendimento, devido a utilização de variedades de mandioca não melhoradas, com baixo potencial produtivo e susceptíveis à doenças.

Entre as doenças que afetam a cultura da mandioca destacam-se as causadoras de manchas foliares como mancha-parda, mancha branca, queima das folhas e mancha preta (Teri et al., 1980). Em programa de melhoramento da mandioca é de fundamental importância detectar a resistência de clones, linhagens ou cultivares ao patógeno em locais onde a doença ocorre com frequência.

Assim, o presente trabalho teve como objetivo estudar o progresso de doenças que causam manchas foliares em condições de campo com infestação natural de forma a determinar o nível de resistência e ou suscetibilidade de 13 variedades de mandioca de

\footnotetext{
${ }^{1}$ Acadêmica de agronomia UFRR, CEP: 69300-000 Boa Vista, RR, Bolsista PIBIT/CNPq, e-mail: hananda hellen@hotmail.com

${ }^{2}$ Doutor em Genética e Melhoramento de Plantas, Embrapa Roraima, Rodovia BR 174, km 08, Distrito Industrial, Boa Vista-RR, e-mail: everton.souza@embrapa.br

${ }^{3}$ Acadêmica de agronomia UFRR, CEP: 69300-000 Boa Vista, RR, Bolsista PIBIC/CNPq, Embrapa Roraima, Rodovia BR 174, km 08, Distrito Industrial, Boa Vista-RR, e-mail: taise pereira19 @ hotmail.com

${ }^{4}$ Acadêmico de agronomia, Fares, Boa Vista-RR. Bolsista macroprograma da Embrapa Roraima, Rodovia BR 174, km 08, Distrito Industrial, Boa Vista-RR, e-mail: la.anghinoni@hotmail.com

${ }^{5}$ Doutora em Fitopatologia, Embrapa Roraima, Rodovia BR 174, km 08, Distrito Industrial, Boa Vista-RR, e-mail: hyanameyka.lima@embrapa.br.
} 
indústria cultivadas em área de cerrado e de 14 variedades cultivadas em área de mata alterada em Roraima.

\section{Fundamentação Teórica}

Em 2009, a Embrapa Roraima começou a participar de um projeto em rede de mandioca, que tem abrangência nacional, participam cultivares introduzidas dos Bancos de Germoplasma das Embrapa de Cruz das Almas-BA, Manaus-AM e Planaltina-DF, além de cultivares coletadas no Estado que atuam como testemunhas para comparação de comportamento. As avaliações consistem em ensaios com repetições, nos ecossistemas de mata alterada e de Cerrado para melhor caracterização dos materiais adaptados. Em Roraima, o cultivo de mandioca para consumo in natura é conduzido em geral sem uso de insumos, sob manejo inadequado e empregando cultivares suscetíveis a doenças (Nechet \& Halfeld-Vieira, 2010). Duas espécies de fungo do gênero Passalora foram identificadas em Roraima associadas às manchas foliares, sendo Passalora henningsii (Cercosporidium henningsii) e Passalora vicosae (Cercospora vicosae), agentes causais das doenças conhecidas como mancha-parda da folha e mancha parda grande, respectivamente. A diferenciação das espécies é baseada em caracteres morfológicos de conídios. Em programa de melhoramento da mandioca é de fundamental importância detectar a resistência de clones, linhagens ou cultivares ao patógeno em locais onde a doença ocorre com frequência.

\section{Metodologia}

No período de junho de 2017 a junho de 2018 foram conduzidos dois experimentos utilizando 13 cultivares de mandioca, sendo um no campo experimental do Água Boa (CEAB), em área de cerrado, no município de Boa Vista/RR e outro no Campo Experimental Serra da Prata (CESP), em área de mata alterada, no município de Mucajaí/ RR, ambos pertencentes a Embrapa Roraima. As cultivares utilizadas nos experimentos são provenientes dos Bancos de Germoplasma da Embrapa Mandioca e Fruticultura Tropical, Embrapa Cerrados e cultivares locais. Foram utilizadas manivas de $20 \mathrm{~cm}$ de comprimento no plantio e a profundidade foi de $10 \mathrm{~cm}$. A adubação de plantio constou da aplicação de $400 \mathrm{~kg} \cdot \mathrm{ha}^{-1} \mathrm{de}$ NPK (08-28-16) e $50 \mathrm{~kg} \cdot \mathrm{ha}^{-1}$ de FTE BR-12. A realização da adubação de cobertura foi aos 50 dias do plantio com $50 \mathrm{~kg} \cdot \mathrm{ha}^{-1}$ de $\mathrm{N}$ na forma de ureia e $40 \mathrm{~kg}^{-h^{-1}}$ de $_{2} \mathrm{O}$ como cloreto de potássio. $\mathrm{O}$ delineamento experimental utilizado foi o de blocos casualizados, com 13 
tratamentos, três repetições, com parcelas de 40 plantas, constituídas de 4 linhas de plantio no espaçamento de 1,0 m x 0,60 m. Cada tratamento correspondeu a uma cultivar de mandioca de indústria, sendo a cultivar IAC 12 considerada como testemunha (Tabela 1).

Tabela 1. Cultivares de mandioca de indústria cultivadas em área de cerrado no campo experimental do Água Boa (CEAB), no município de Boa Vista/RR e em área de mata alterada no Campo Experimental Serra da Prata (CESP), no município de Mucajaí/ RR, Brasil

\begin{tabular}{lllll}
\hline $\begin{array}{c}\text { Trata- } \\
\text { mentos }\end{array}$ & \multicolumn{1}{c}{ Cultivares } & \multicolumn{1}{c}{ Origem } & \multicolumn{1}{c}{ Cidade } & \multicolumn{1}{c}{ Estado } \\
\hline T1 & Amarelona & Embrapa Roraima & Boa Vista & Roraima \\
T2 & Amansa Burro & Embrapa Mandioca e Fruticultura & Cruz das Almas & Bahia \\
T3 & Clone 3 & Embrapa Cerrados & Planaltina & D. Federal \\
T4 & BRS Aramaris & Embrapa Mandioca e Fruticultura & Cruz das Almas & Bahia \\
T5* & IAC 12 & Embrapa Cerrados & Planaltina & D. Federal \\
T6 & BRS Formosa & Embrapa Mandioca e Fruticultura & Cruz das Almas & Bahia \\
T7 & Inajazinha & Embrapa Roraima & Rorainópolis & Roraima \\
T8 & Jacona & Embrapa Roraima & Rorainópolis & Roraima \\
T9 & BRS Guaíra & Embrapa Mandioca e Fruticultura & Cruz das Almas & Bahia \\
T10 & BRS Kiriris & Embrapa Mandioca e Fruticultura & Cruz das Almas & Bahia \\
T11 & BRS Mulatinha & Embrapa Mandioca e Fruticultura & Cruz das Almas & Bahia \\
T12 & BRS Prata & Embrapa Mandioca e Fruticultura & Cruz das Almas & Bahia \\
T13 & Clone 98150-06 & Embrapa Mandioca e Fruticultura & Cruz das Almas & Bahia \\
& Ena & \\
\hline
\end{tabular}

*Testemunha;

No período de fevereiro até junho de 2018, foi realizado o monitoramento da ocorrência de manchas foliares nas 13 cultivares de mandioca de indústria nos dois campos experimentais. Amostras de folhas com sintomas de doença foram enviadas ao laboratório de Fitopatologia da Embrapa Roraima para diagnose do agente causal da doença. A intensidade da doença, originada a partir de infecção natural em campo, foi quantificada em cinco plantas de cada parcela, em intervalos de 30 dias, totalizando cinco avaliações que se encerraram por ocasião da colheita. As variáveis avaliadas em cada planta foram: incidência e severidade da doença. A severidade da doença foi estimada com auxílio de escala de notas conforme descrito por Santos et al. (2004). Para realização das análises, as notas atribuídas conforme avaliação da severidade da doença observada em cada planta/cultivar foi convertida para o índice de doença de MacKinney. Com os dados de severidade, construíram-se curvas e calcularam-se os valores da área abaixo da curva de progresso da doença (AACPD) para cada cultivar, conforme Campbell \& Madden (1990). Também foi determinado a severidade 
máxima (Ymax) que ocorreu durante o período de realização das cinco avaliações da doença em campo. Os dados de AACPD e Ymax foram submetidos à análise de variância (ANOVA) e as médias comparadas pelo teste de Scott-Knot.

\section{Resultados e Discussões}

Das cinco avaliações realizadas em campo, foi possível identificar a incidência do fungo Passalora henningsii (Cercosporidium henningsii) agente causal da doença manchaparda da folha em todas as cultivares de mandioca avaliadas. Os valores de AACPD demonstraram que houve variação no progresso da doença entre as diferentes cultivares apenas na área de cerrado. Os tratamento T1, T2, T4 e T13 apresentaram os maiores valores de AACPD. Quanto maior o valor de AACPD mais rápido foi o progresso da doença durante o período de avaliação. Por outro lado, os valores de Ymax, que representam a severidade máxima observada em campo, não apresentou diferença significativa entre as cultivares avaliadas tanto em área de cerrado quanto em área de mata alterada (Tabela 2).

Tabela 2. Dados de estimativa da intensidade da mancha-parda das folhas durante o período de fevereiro a junho de 2018, representada pela Área Abaixo da Curva de Progresso da Doença (AACPD) e pela Severidade máxima da doença (Ymax) observada em campo em 13 cultivares de mandioca de indústria cultivadas em área de cerrado e de mata alterada em Roraima, Brasil. Fonte Própria

\begin{tabular}{clcccc}
\hline & & \multicolumn{2}{c}{ Área de Cerrado } & \multicolumn{2}{c}{ Área de Mata Alterada } \\
\hline Tratamentos & Cultivares & AACPD & Ymax $(\%)$ & AACPD & Ymax $(\%)$ \\
\hline T1 & Amarelona & $2875 \mathrm{a}$ & $30 \mathrm{a}$ & $2900 \mathrm{a}$ & $32 \mathrm{a}$ \\
T2 & Amansa Burro & $3038 \mathrm{a}$ & $30 \mathrm{a}$ & $2488 \mathrm{a}$ & $24 \mathrm{a}$ \\
T3 & Clone 3 & $2588 \mathrm{~b}$ & $27 \mathrm{a}$ & $2663 \mathrm{a}$ & $28 \mathrm{a}$ \\
T4 & BRS Aramaris & $3100 \mathrm{a}$ & $36 \mathrm{a}$ & $2338 \mathrm{a}$ & $26 \mathrm{a}$ \\
T5 & IAC 12* & $2738 \mathrm{~b}$ & $27 \mathrm{a}$ & $2638 \mathrm{a}$ & $28 \mathrm{a}$ \\
T6 & BRS Formosa & $2738 \mathrm{~b}$ & $27 \mathrm{a}$ & $2563 \mathrm{a}$ & $25 \mathrm{a}$ \\
T7 & Inajazinha & $2563 \mathrm{~b}$ & $31 \mathrm{a}$ & $2738 \mathrm{a}$ & $32 \mathrm{a}$ \\
T8 & Jacona & $2563 \mathrm{~b}$ & $27 \mathrm{a}$ & $2963 \mathrm{a}$ & $29 \mathrm{a}$ \\
T9 & BRS Guaíra & $2675 \mathrm{~b}$ & $32 \mathrm{a}$ & $2713 \mathrm{a}$ & $30 \mathrm{a}$ \\
T10 & BRS Kiriris & $2663 \mathrm{~b}$ & $29 \mathrm{a}$ & $2738 \mathrm{a}$ & $28 \mathrm{a}$ \\
T11 & BRS Mulatinha & $2788 \mathrm{~b}$ & $30 \mathrm{a}$ & $2688 \mathrm{a}$ & $28 \mathrm{a}$ \\
T12 & BRS Prata & $2650 \mathrm{~b}$ & $27 \mathrm{a}$ & $2313 \mathrm{a}$ & $25 \mathrm{a}$ \\
T13 & Clone 98150-06 & $3038 \mathrm{a}$ & $33 \mathrm{a}$ & $2950 \mathrm{a}$ & $30 \mathrm{a}$ \\
\hline
\end{tabular}

*médias seguidas de mesma letra na coluna pertencem ao mesmo agrupamento pelo teste de Scott-Knott, não diferindo ao nível de $5 \%$ de probabilidade. 
A ocorrência de alta severidade desta doença, confirmada pelos dados de AACPD e Ymax de algumas cultivares (Tabela 2), ocorreram provavelmente devido ao clima, pois o período de avaliações da severidade da doença em campo ocorreram em períodos de altas precipitações pluviométricas, sendo que a estação chuvosa é mais favorável à ocorrência da cercosporiose, sendo o vento e a chuva os principais meios de disseminação da doença e a temperatura ótima para a germinação é de $39^{\circ} \mathrm{C}$ e umidade de $90 \%$ (Nechet \& Halfeld-Vieira, 2010).

\section{Conclusões}

Houve ocorrência da doença mancha-parda das folhas causada pelo fungo Passalora henningsii em todas as cultivares avaliadas e os valores de Ymax demonstraram que não houve variação da severidade máxima da doença observada em campo entre as diferentes cultivares, tanto em área de cerrado quanto em área de mata alterada. As cultivares Amarelona, Amansa burro, BRS Aramaris e clone 98150-06 apresentaram maior AACPD em área de cerrado, demonstrando que o progresso da doenças em tais cultivares foi mais rápido, devendo assim evitar o cultivo das mesmas em área de ocorrência favorável para mancha-parda.

\section{Referências}

ALVES M. C. S., MOREIRA M. A. B., CHAGAS M. C. M., HOLANDA J. C., SILVA J., JUAREZ DAMASCENO DE SOUZA LIMA J. D. S. M.. Recomendações técnicas para o cultivo da mandioca. VI Circuito de tecnologias adaptadas para a agricultura familiar. Natal, RN. 2009.

CAMPBELL, C. L \& MADDEN, L. V. Introduction to plant disease epidemiology. New York NY, Wiley, 1990.

NECHET, K.L \& HALFELD-VIEIRA, B. A. Identificação e manejo de doenças da mandioca em Roraima. Boa Vista. Embrapa Roraima, 2010. 05p. (Embrapa Roraima, Comunicado Técnico, 53).

SANTOS, R.P.; CARMO, M.G.F.; PARRAGA, M.S.; MACAGNAN, D.; LOPES, C.A. Avaliação de cultivares de mandioca, para consumo in natura, quanto à resistência à mancha parda da folha. Horticultura Brasileira, Brasília, v.22, n.2, p.232-237, 2004.

TERI, J.M.; THURSTON, H.D.; LOZANO, J.C. Effect of brown leaf spot and cercospora leaf blight on cassava productivity. Tropical Agriculture, v.57, n.3, p.239-243, 1980. 